\title{
NSAID-associated mucosal damage and ulceration - Incidence, etiology, prophylaxis and treatment
}

\author{
MALCOLM CCHAMPION, MB, FRCPC, FRCP(UK)
}

MC CHAMPION. NSAID-associated mucosal damage and ulceration - Incidence, etiology, prophylaxis and treatment. Can J Gastroenterol 1993;7(5): 427-439. There is increasing evidence that nonsteroidal anti-inflammatory drug (NSAII) -associated mucosal damage is causing considerable morbidity and mortality, Mucosal damage can be manifested by hemorrhage, erosions or ulceration and occurs mostly in the stomach but also in the duodenum. At least $50 \%$ of ulcers are silent and may present initially with either a gastrointestinal bleed or perforation. The NSAID-associated ulcer appears to be partially mediated by prostaglandin inhibition and occurs most frequently in elderly patients. Studies, which have addressed symptom improvement with the $\mathrm{H}_{2}$ receptor antagonists, sucralfate and misoprostol, have been disappointing overall in improving symptoms compared with placebo. The $\mathrm{H}_{2}$ receptor antagonists have demonstrated efficacy in the prophylaxis of NSAID-associated duodenal ulcers but not gastric ulcers. Treatment studies with the $\mathrm{H}_{2}$ receptor antagonists have demonstrated some efficacy in healing NSAID-associated duodenal ulcers but not gastric ulcers while the NSAID therapy is continued. Sucralfate has been shown to heal NSAID-associated duodenal ulcers while the NSAID was continued but not improve gastric mucosal damage. Omeprazole in a small number of patients healed NSAID-associated gastric ulcers while the NSAID was continued. Misoprostol has demonstrated efficacy in the prophylaxis and treatment of NSAID-associated gastric ulcers and also in the prophylaxis of NSAID-associated duodenal ulcers. The patient at most risk from taking NSAIDs appears to be the elderly patient with a previous history of peptic ulcer disease, and may be associated with large doses of NSAIDs and concomitant therapy with prednisone.

Key Words: Duodenal ulcers, Gastric ulcers, Mucosal damage, NSAIDs

Lésions et ulcérations des muqueuses associées aux AINS, incidence, étiologie, prophylaxie et traitement

RÉSUMÉ: On constate de plus en plus que les lésions occasionnées par les anti-inflammatoires non stéroïdiens (AINS) donnent lieu à des taux de morbidité et de mortalité considérables. Les lésions des muqueuses peuvent se manifester par des hémorragies, des érosions ou des ulcérations et se produisent surtout au niveau de l'estomac, mais aussi du duodénum. Au moins $50 \%$ des ulcères sont silencieux et peuvent se manifeste d'abord par une hémorragie digestive ou une perforation. Les ulcères liés aux AINS semblent en partie modulés par l'inhibition des pro-

Division of Gastroenterology, Ottawa Civic Hospital, Ottawa, Ontario

Correspondence: Dr MC Champion. Diviston of Gastroenterology, Ottawa Civic Hospital. 1053 Carling Avenue, Ottawa, Ontario KIY 4E9. Telephone (613) 761-4674
THIS ARTICLE REVIEWS THE INCI

dence, etiology, prophylaxis and treatment of nonsteroidal anti-inflammatory drug (NSAID)-associated mucosal damage and ulceration. The term NSAID will be used to address both acetylsalicylic acid (ASA) and non-ASA NSAIIS.

\section{INCIDENCE}

There are at least four million patients in Canada with arthritis. There are on average 10 million prescriptions each year for NSAIDs and there are at least 1.9 million patients on continuous NSAID therapy (1). The Federal Drug Administration (FDA) in the United States estimates that there are 200,000 cases of gastrointestinal (GI) bleeding with 10,000 to 20,000 deaths occurring each year due to the 68 million prescriptions of NSAIDs for arthritis (2). These figures can be extrapolated to the Canadian population with an estimated annual incidence of 20,000 GI bleeds and 1000 to 2000 deaths due to NSAII)s. If these figures are correct, then the mortality due to NSAIDs is greater than the present annual mortality from acquired immunodeficiency syndrome (AIDS) in Canada.

NSAIDs have been associated with adverse effects on the gastric $(3,4)$ and duodenal mucosa $(5,6)$ and this has been well documented in many studies. These adverse side effects vary from symptoms of bleeding from gastritis or 
staglandines et surviennent le plus fréquemment chez les malades âgés. Des études qui ont porté sur l'amélioration de la symptomatologie avec les anti- $\mathrm{H}_{2}$, le sucralfate et le misoprostol ont toutes globalement donné lieu à des résultats décevants pour ce qui est de l'amélioration des symptômes, en comparaison avec le placebo. Les anti- $\mathrm{H}_{2}$ ont été efficaces en prophylaxie des ulcères duodénaux liés aux AINS, mais non des ulcères gastriques. Les études sur les thérapeutiques avec anti- $\mathrm{H}_{2}$ ont montré une certaine efficacité à guérir les ulcères duodénaux liés aux AINS, mais non les ulcères gastriques durant la poursuite du traitement aux AINS. Le sucralfate s'est révélé efficace à faire cicatriser les ulcères duodénaux liés aux AINS durant la poursuite du traitement aux AINS, mais ne s'est pas révélé efficace à améliorer les lésions de la muqueuse gastrique. L'oméprazole chez un faible nombre de patients a guéri les ulcères gastriques liés aux AINS durant la poursuite du traitement aux AINS. Le misoprostol s'est révélé efficace en prophylaxie et en thérapeutique des ulcères gastriques et en prophylaxie des ulcères duodénaux liés aux AINS. Le patient chez qui la prise d'AINS est la plus risquée semble être le patient âgé qui a déjà des antécédents d'ulcère gastroduodénal, et le risque semble être proportionnel à la dose d'AINS et à la concomitance d'un traitement à la prednisone.

duodenitis to ulceration which may progress to significant Gl bleeding or perforation. In a study hy Lanza (7) side effects were shown to be dose related and can he associated with either the use of ASA or mon-ASA NSAIDs. These side effects occurred not only with oral administration but can occur with either rectally or systemically administered NSAII)s (8). Further evidence for the systemic action of NGAlls in damaging the Gl mucosa is provided by the use of sulindac. Sulindac is a pro-drug requiring absorption and metabolism in the liver before it develops anti-inflammatory or other biological actions. Sulindac has heen implicated as one of the leading causes of upper GI bleeding within 30 days of starting NSAll) therapy (9).

Although there is considerable evidence linking consumption of NSAIIs and development of gastric ulcers, to date there has heen less evidence implicating NSAIDs as a cause of duodenal mucosal damage or duodenal ulcers $(5,6)$. However the increased incidence of duodenal ulcers in NSAII) users, as demonstrated by McCarthy (10), is supporting evidence that NSAIIs cause mucosal damage not only to the stomach but also the duodenum. More distally, in the small howel absorption of permeability markers has been shown to be increased in up to $70 \%$ of patients taking NSAIDs (11). NSAII)s have also been implicated in small bowel mucosal ulceration (12).
Mc Carthy (10) reviewed the prevalence of ulceration related to NSAII)s and demonstrated that the crude prevalence estimate for gastric ulcers was $13 \%$ of arthritis NSAID users compared with the gastric ulcer prevalence of $0.28 \%$ in the normal population. This yielded a relative increased risk of 46 times for developing a gastric ulcer for patients taking NSAII)s. McCarthy also estimated that the crude prevalence estimate for duodenal ulcer was $11 \%$ with a normal prevalence of $1.2 \%$. This yielded a relative risk of eight times increased duodenal ulceration in patients taking NSAIDs. This review demonstrated that if NSAID use was a causal factor the user was six times more likely to develop a gastric ulcer than a duodenal ulcer as a consequence of NSAID therapy. In two recent publications not covered by McCarthy's review the ratio of gastric to duodenal ulcer has been lower at 1.5:1 $(13,14)$. Despite the increased mucosal damage to the stomach, studies of ulcer complications have demonstrated equal risks for gastric and duodenal uleer bleeding and perforation (15).

The fact that endoscopic damage is remarkably common was demonstrated in a study by Larkai et al (16) in 65 patients receiving chronic NSAID therapy for rheumatoid arthritis and osteoarthritis who were evaluated endoscopically. All of these patients had been on therapeutic doses of NSAIIs for at least six weeks and were not receiv- ing any other drugs known to cause mucosal damage. At endoscopy only $32 \%$ of the patients had a normal mucosa. The remaining $68 \%$ had abnormal endoscopic findings and these varied from mucosal hemorrhage (45\%) and erosions ( $54 \%$ ) to gastric or duodenal ulceration $(15 \%)$.

Of all adverse drug reactions (ADRs) reported to the Health Protection Branch (HPB) of Health and Welfare Canada, 10\% are due to NSAlls (17). It is well accepted that ADRs reported to the HPB give only a conservative estimate of the problem of side effects. In an analysis of NSAII)-induced upper Gl hleeding, perforation and ulcers spontaneously reported to the FDA, all the NSAlls approved for use were associated to some degree with serious adverse gastrointestinal effects (18).

Langman (19) has reviewed the epidemiological evidence of association between ulceration and NSAII) use. He demonstrated that there was evidence to suggest a doubling or quadrupling of the risk of ulcer complications or death in patients receiving NSAlDs. The risk appeared to be related to increasing age. Langman has also demonstrated that the incidence of ulceration is decreasing in the younger population and increasing in the elderly (20). At least part of this change was thought to reflect the frequent prescribing of NSAIDs in the elderly population. In a large epidemiological study in the state of Tennessee, Griffin (21) demonstrated that elderly patients (over 60) taking NSAIIs were four times more likely to die from perforation or peptic ulcer disease than patients not taking NSAIDs. In another study, Griffin demonstrated that the estimated relative risk of the development of peptic ulcer disease among current users of NSAIIs compared with that of nonusers was $4.1 \%$. The risk increased with increasing doses of NSAILs and was greatest in the first month of use. It was estimated that $29 \%$ of peptic ulcers in the study sample of 1415 patients hospitalized for confirmed peptic ulcer disease resulted from NSAIIS. The excess risk associated with such use was $17.4 \%$ hospitalization for ulcer disease per 1000 personyears of exposure (22). In a study by 


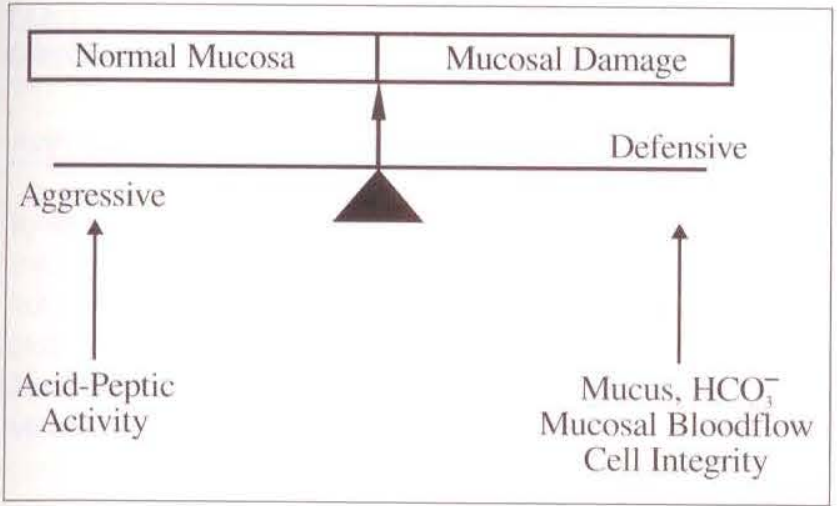

Figure 1) Etiology of nonsteroidal anti-inflammatory drug-associated mucosal damage. There is a fine balance between normal mucosa and mucosal damage in the stomach and duodenum. This is a balance between aggressive factors and defensive factors

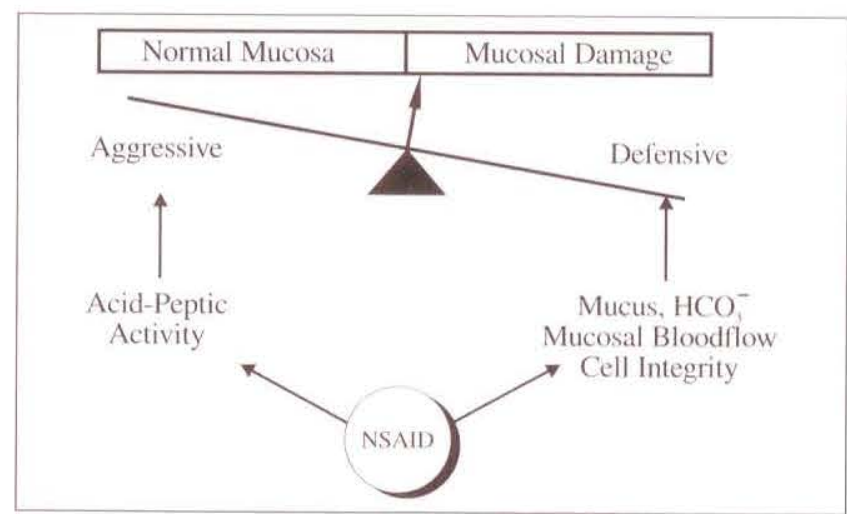

Figure 2) Etiology of nonsteroidal anti-inflammatory drug (NSAID) -associated mucosal damage. NSAIDs decrease the defensive factors and increase the aggressive factors. Other factors include: vascular damage, leukocyte migration, mucosal damage from oxygen free radicals and delayed healing
Kurata and Abbey (23) there were 23 duodenal ulcer and 14 gastric ulcer hospitalizations during a three-year followup study of 4524 subjects taking part in the Aspirin Myocardial Infarction Study. In this study, patients were randomized to either $1 \mathrm{~g}$ of ASA per day or placebo for three years. The relative risk for duodenal ulcer hospitalization was 10.7 times higher for the ASA group than for the placebo group $(\mathrm{P}<0.001)$. The relative risk of gastric ulcer hospitalization was $9.1(P=0.04)$.

Gabriel (24), in a meta-analysis, examined the association between NSAIDs and adverse GI events in 16 studies. Users of NSAIDs appeared to be at approximately a three times greater risk of developing serious adverse events than non-users. Additional risk factors included: age greater than 60 years; previous history of GI events; concomitant corticosteroid use; and the first three months of NSAID therapy. The risk for serious problems ap. peared to be equal in men and women.

The American Rheumatism Association Medical Information System (ARAMIS) has followed 2747 patients with rheumatoid arthritis and $1091 \mathrm{pa}$ tients with osteoarthritis. The yearly hospitalization incidence during NSAID treatment was $1.58 \%$ in the rheumatoid arthritis patients. The hazard ratio in patients taking NSAIDs to those not taking NSAIDs was $5.2 \%$. The hazard ratio in patients taking NSAIDs for osteoarthritis appeared to be less. The risk of GI related deaths in rheumatoid arthritis patients was $0.19 \%$ per year with NSAIDs. The main risk factors were higher age, use of prednisone, previous NSAII) GI side effects, prior GI hospitalization, level of disability and NSAID dose (25). The ARAMIS data have also estimated that NSAID-associated Gl mucosal damage in patients with rheumatoid arthritis may account for up to 1260 deaths, 20,000 hospitalizations and a cost of $\$ 200$ million per year in the United States (26). It is estimated that less than 10\% of NSAII prescriptions are for patients with rheumatoid arthritis.

The working party report at the World Congress of Gastroenterology in Sydney, Australia in 1990, chaired by Dr Langman, looked at the epidemiology, causation and treatment of NSAID. associated ulcer.

This working party concluded that the individual risk of serious complications is low but the population risk is high because NSAIDs are commonly used. The associated risk factors were not fully understood but there was incontrovertible evidence that the use of NSAIDs was associated with the devel. opment of gastric ulcers, ulcer complications, gastric and duodenal ulcer bleeding and with death due to ulcer. They felt that it was unclear whether NSAID treatment predisposed to duodenal ulceration. The working party did not give any firm recommendations for prophylaxis but felt that some evidence was accumulating for the efficacy for the prostaglandins in preventing gastric ulcers and of the $\mathrm{H}_{2}$ receptor antagonists in preventing duodenal ulcers (15).
These data on the incidence and mortality related to mucosal damage from patients taking NSAIDs have resulted in the FDA producing a new product insert warning patients of the risk of taking NSAIDs (21). The Australian government has also recently restricted the prescriptions of NSAIDs and the product inserts for NSAIIs in Canada are under review by the HPB.

\section{ETIOLOGY}

It is commonly observed in reviews of the medical literature on ulcer therapy that peptic ulcer disease results from an imbalance between gastric secretion and gastric mucosal resistance (28-30). There is a fine balance between normal mucosa and mucosal damage in the stomach and duodenum. This is a balance between aggressive factors (acid and acid-peptic activity) and defensive factors (mucus, gastric bicarbonate secretion, blood flow and cell integrity) (Figure 1). A patient taking NSAIDs upsets this balance by prostaglandin inhibition which results in a decrease of the defensive factors. There is also some evidence that NSAIDs may increase the aggressive factors by increasing acid production (31). In addition to prostaglandin inhibition, other factors which have been suggested as playing a role in NSAID-associated mucosal damage include: microvascular damage to venules with reduction of mucosal bloodflow (32); vascular congestion secondary to neutrophil adhesion to the vascular endothelium associated with leukocyte migration 
TABLE 1

Clinical studies in the treatment of NSAID-associated gastrointestinal symptoms

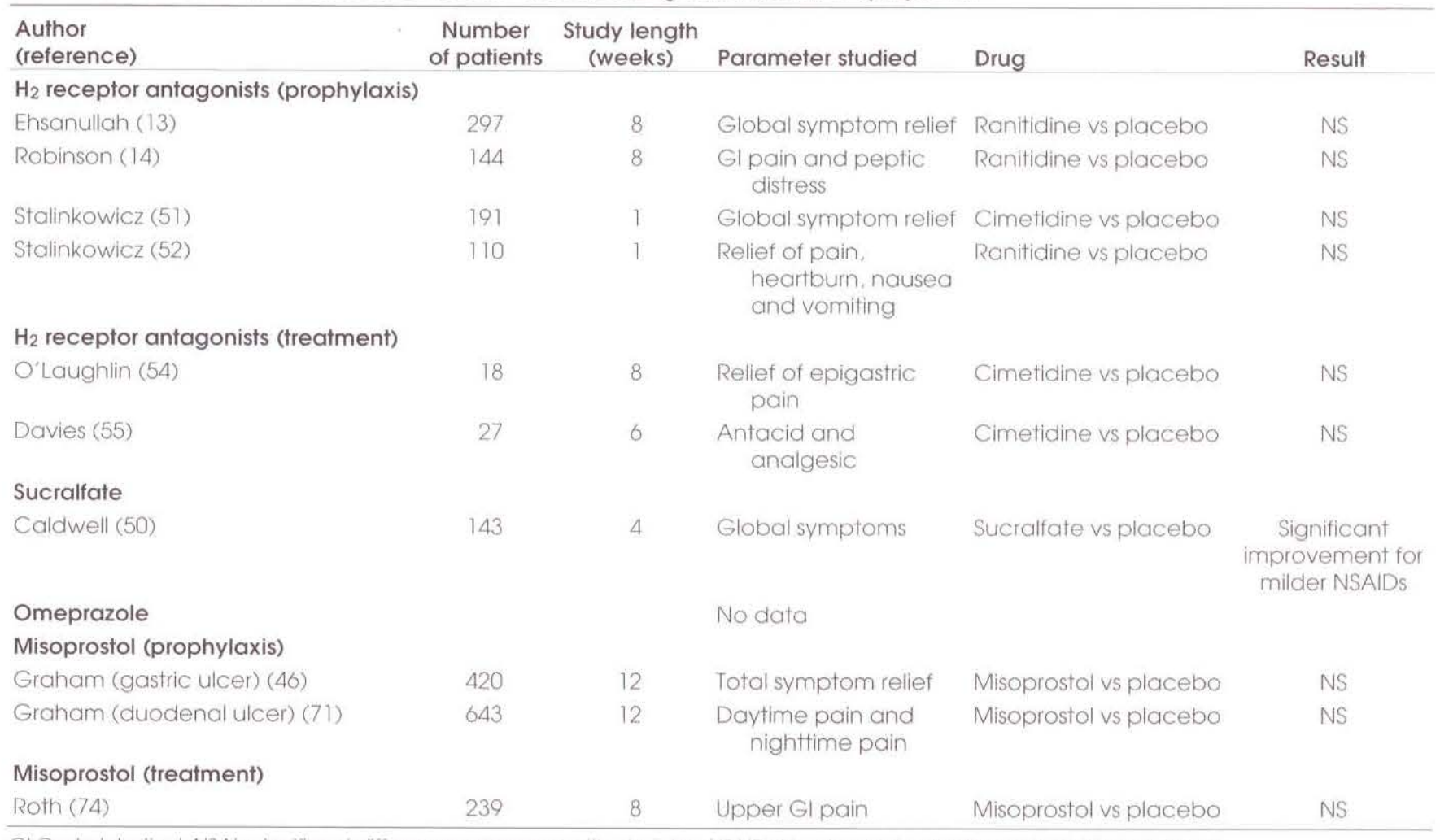

Gl Gastrointestinal: NS No significant difference compared with placebo; NSAIDs Nonsteroidal anti-inflammatory drugs: vs Versus

within the mucosa $(33,34)$; increased production of neutrophil generated oxygen-derived free radicals with resultant mucosal damage (35); and delayed cell proliferation and ulcer healing (36). Thus a patient taking NSAIDs tips the balance from normal mucosa to mucosal damage and it is these patients who develop the gastritis, duodenitis, erosions and ulceration found in patients on NSAIDs (Figure 2).

In a recent review into the mechanism of NSAID)-associated gastric damage, Schoen and Vender postulated a dual mechanism of injury (37). The primary insult is by an acid-mediated topical effect of the NSAII) on the mucosa. ASA and most other NSAILs are weak organic acids. This action combined with an NSAll-associated stimulation of acid production (31), together with vascular damage and an inflammatory neutrophil reaction, results in mucosal damage (32-35). Once this topical damage begins it is compounded by the NSAID-mediated prostaglandin inhibition which results in inhibition of mucosal healing (36).
Roth and Bennett (38) summarized the difference between an acid-mediated ulcer and an NSAID-associated ulcer. An NSAID-associated ulcer appears to he mediated by prostaglandin inhibition secondary to NSAll) ingestion, which principally decreases the mucosal defenses. In addition, NSAIDs possibly mediate their mucosal damage by a variety of other mechanisms (31-36). These ulcers occur more commonly in the antrum and the prepyloric area and, contrary to acid-mediated ulcers, are more common in older patients. Finally, acid-mediated ulcer disease recurrence, particularly duodenal ulcers, has been strongly associated with Helicobacter pylori. The prevalence of $\mathrm{H}$ pylori does not appear to be increased in patients with NSAlD-associated ulceration (39). There has been some suggestion that H pyloni may be associated with NSAID-associated mucosal damage (40) but other studies have not shown an association (41).

Resistance to further damage with a return to a normal mucosa despite continued exposure to the NSAID is termed adaptation. This may be prostaglandinmediated (42). Graham (43) found that decreasing damage occurred with continued exposure to ASA. Adaptation was more rapid with a lower ASA dose $(1.3 \mathrm{~g} /$ day $)$ than at a higher dose $(2.6 \mathrm{~g} / \mathrm{day})$. These findings have been supported in epidemiological studies where the risk of complications appeared to be highest in the initial period of NSAII) ingestion $(9,21)$. Contrary to these studies, other endoscopically controlled studies have found no evidence of adaptation $(44,45)$. Epidemiologically, Kurata and Abbey (23) have also demonstrated no decreased risk for hospitalization for gastric or duodenal ulcers in long term prophylactic treatment with ASA. Whether adaptation is clinically important in patients taking NSAIDs remains controversial. Even if adaptation is important there is still a high incidence of gastric ulcers which range from 6 to $25 \%(13,43)$ in patients who have been on NSAII) for at least three months,

This different etiology from acid- 
TABLE 2

Clinical studies in prophylaxis of NSAID-induced mucosal damage and ulceration

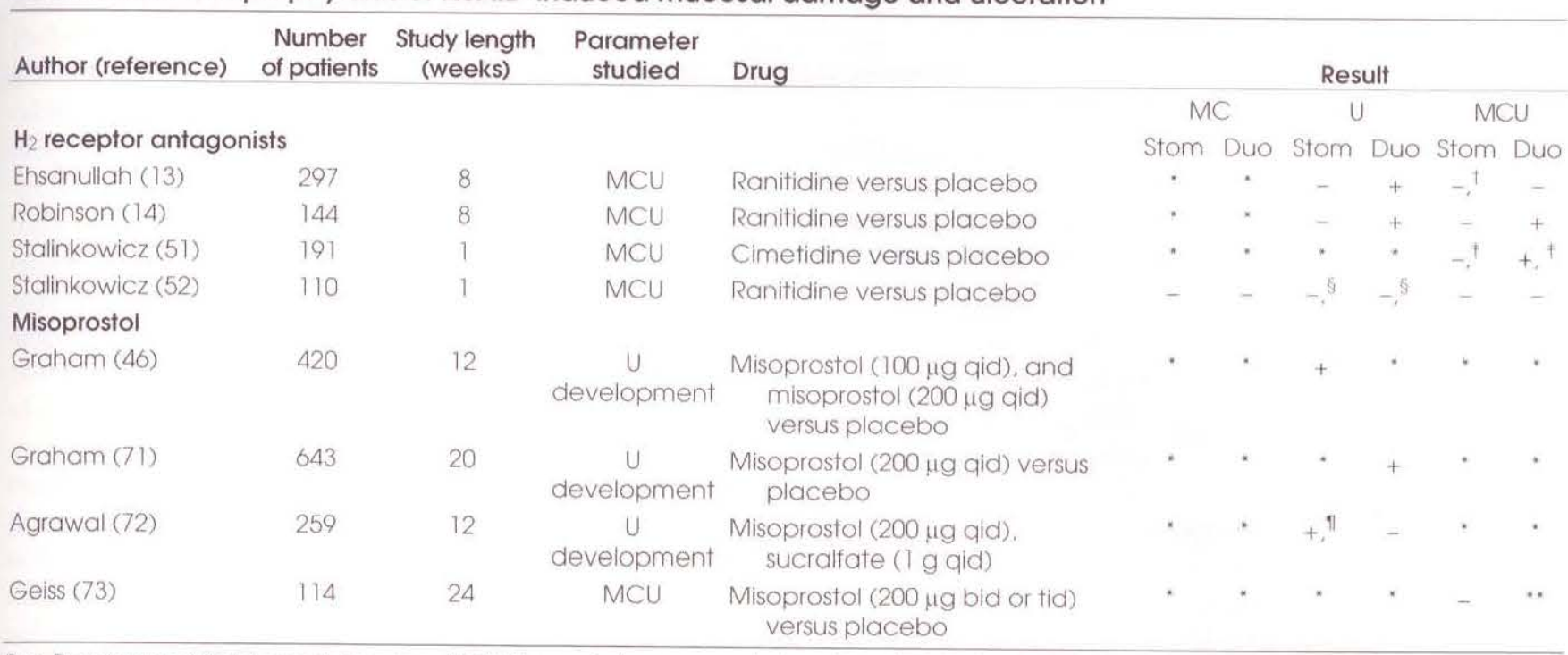

Duo Duodenum: MC Mucosal damage: MCU Mucosal damage and ulceration: NSAIDS Nonsteroidal anti-inflammatory drugs: Stom Stomach U Ulceration: - Not significant: + Significant difference $(P<0.05)$ compared with placebo: "No data: "Benefit demonstrated at week 4 not demonstrated at week 8: Data for cimetidine $400 \mathrm{mg}$ bid. All data for cimetidine $400 \mathrm{mg}$ at beditime show no difference compared with placebo: $5 \mathrm{Small}$ number of patients; "Significant difference compared with sucralfate: "Significant improvement for gastroduodenal lesions but not gastric lesions

mediated ulcer disease has to be considered when one addresses the prophylaxis and treatment of NSAID-associated mucosal damage and ulceration.

\section{PROPHYLAXIS AND TREATMENT}

This section deals with the prophylaxis and treatment of symptoms and also NSAID-associated mucosal damage and ulceration. It will review only peerreviewed controlled clinical studies in patients on the $\mathrm{H}_{2}$ receptor antagonists, omeprazole, sucralfate and misoprostol. Open studies and those studies only published in abstract form will not be reviewed. The efficacy of these therapies in improving symptoms is summarized in Table 1. The prophylactic studies are summarized in Table 2 and the treatment studies in Table 3.

Symptoms: There is poor correlation between symptoms and mucosal ulceration which means the physician cannot rely on symptoms for predicting which patients have or are developing ulceration. However, indigestion and dyspepsia are remarkably common and have been reported to occur in up to $38 \%$ of patients on NSAIDs. It is one of the most common reasons for patients discontinuing NSAIDs. In the study by Larkai et al (16) $68 \%$ of patients receiving chronic NSAID therapy had mucosal damage, yet few of the patients were symptomatic. Of 44 patients with abnormal endoscopic findings, $91 \%$ had no symptoms and seven of the $10 \mathrm{pa}$ tients with ulcers were asymptomatic.

GI complications due to NSAIDs can present spontaneously with a significant upper GI bleed or perforation with no premonitory symptoms. It has been estimated that at least $50 \%$ of NSAIDassociated ulcers are asymptomatic. In a retrospective study of 235 patients who either died or required surgery because of bleeding or perforated ulcers, $60 \%$ of these patients with life threatening ulcer complications were on NSAID therapy compared with $9.9 \%$ of a hospital controlled group on NSAID therapy. Only 25\% of the patients who had not been taking NSAIDs had no previous symptoms consistent with peptic ulcer disease. Fifty-eight per cent of those patients who had a history of NSAID use had no symptoms hefore their complications. Thus bleeding or perforation was the first sign of ulcer in more than half of those with ulcer complications taking NSAIDs (47). Similarly, findings were documented in a prospective study of dyspepsia by Skander and Ryan (48). In 98 patients aged 65 years and over in whom endoscopy had revealed either gastric or duodenal ulcers, only six of 36 patients
(17\%) aged greater than 75 years who had taken NSAIDs during the six weeks before endoscopy presented with dyspepsia. This is compared with 13 of 20 patients $(65 \%)$ in the same age group who had not taken NSAIDs and had symptoms of dyspepsia $(\mathrm{P}<0.001)$.

These studies suggest that NSAIDS mask the pain that would normally lead to the diagnosis of ulceration. In elderly patients this has serious implications because it could cause a delayed presentation of a severe complication such as bleeding, perforation or anemia. This could lead to an underestimation of the true incidence of ulceration in those people aged 75 years and over, and might explain the worse prognosis of ulcers in the elderly (48).

Table 1 summarizes the efficacy of the $\mathrm{H}_{2}$ receptor antagonists, omeprazole, sucralfate and misoprostol in resolving symptoms compared with placebo in patients taking NSAIDs. On reviewing the studies the $\mathrm{H}_{2}$ receptor antagonists, cimetidine and ranitidine, have no proven benefit in improving symptoms. There are no data on omeprazole in the single study performed in which $14.6 \%$ of patients had NSAIDassociated gastric ulcers (50). Sucralfate improved the intensity and frequency for global symptoms for the milder NSAIDs (nonacetylated and long 


\section{TABLE 3}

Clinical studies in the treatment of NSAID-associated mucosal damage and ulceration while the NSAID was continued

\begin{tabular}{|c|c|c|c|c|c|c|}
\hline \multirow{2}{*}{$\begin{array}{l}\text { Study } \\
\text { (reference) }\end{array}$} & \multirow{2}{*}{$\begin{array}{l}\text { Number } \\
\text { of patients }\end{array}$} & \multirow{2}{*}{$\begin{array}{l}\text { Study } \\
\text { duration* }\end{array}$} & \multirow[b]{2}{*}{ Parameter studied } & \multirow[b]{2}{*}{ Drug } & \multicolumn{2}{|c|}{ Result } \\
\hline & & & & & Stomach & Duodenum \\
\hline \multicolumn{7}{|c|}{$\mathrm{H}_{2}$ receptor antagonists } \\
\hline O'Laughlin (54) & 18 & 8 & $\mathrm{HGU}$ & Cimetidine versus placebo & - & \\
\hline Roth (56) & 104 & 8 & HGMD & Cimetidine versus placebo & - & \\
\hline Lancaster-Smith (57) & 190 & 12 & $\mathrm{HDU}, \mathrm{HGU}$ & $\begin{array}{l}\text { Ranitidine + NSAID versus } \\
\text { ranitidine - NSAID }\end{array}$ & +2 & +2 \\
\hline Walan (49) & 88 & 8 & HGU & Omeprazole versus ranitidine & $+1,-$ & \\
\hline \multicolumn{7}{|l|}{ Sucralfate } \\
\hline Caldwell (50) & 143 & 4 & $\begin{array}{l}\text { Improvement in gastric } \\
\text { mucosal lesions score }\end{array}$ & Sucralfate versus placebo & - & \\
\hline \multicolumn{7}{|c|}{ Sucralfate versus placebo } \\
\hline & & & & Mucosal de & amage: +3 & +3 \\
\hline
\end{tabular}

HDU Healing of duodenal ulcers; HGMD Healing of gastric mucosal damage; HGU Healing of gastric Ulcers; NSAID Nonsteroidal anti-inflammatory drug:

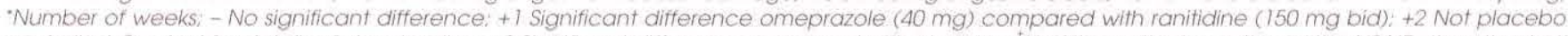

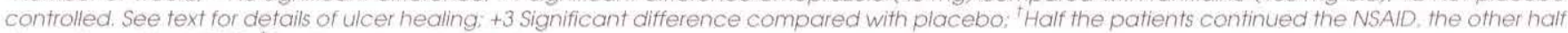
discontinued the NSAID; Small number of patients

half-life NSAII)s). Sucralfate was not effective in improving symptoms for the acetylated or short half-life NSAIDs. Overall symptom scores for sucralfate were significantly reduced for intensity but not for frequency of symptoms (50). Misoprostol has not been shown to be superior to placebo in improving symp. toms compared with placebo. However, in the Graham study (46) total symptom relief was obtained in $70 \%$ to $75 \%$ of patients taking misoprostol versus $56 \%$ for placebo.

These data suggest that we do not have effective therapy for resolving NSAID-associated GI symptoms. It also raises the question as to the etiology of these symptoms because they have a poor correlation with evidence of mucosal damage and do not resolve with healing of documented ulceration.

\section{$\mathrm{H}_{2}$ RECEPTOR ANTAGONISTS}

$\mathrm{H}_{2}$ receptor antagonists effectively suppress acid production but have not been demonstrated to have any effect on the mucosal defensive factors of the upper GI tract. There have been three studies with ranitidine and one with cimetidine which address the prophylaxis against NSAID-associated gastric and duodenal lesions $(13,14,51,52)$.
There have been four studies with cimetidine which addressed treatment of NSAID-associated erosions and ulceration (53-56), and one nonplacebo controlled study with ranitidine which compared the healing of NSAID-associated ulcers with or without continuing the NSAID (57). The study by Roth and colleagues (56) also had a prophylaxis phase at the end of the treatment phase. There have been no studies published with the newer $\mathrm{H}_{2}$ receptor antagonists famotidine and nizatidine. The results of the prophylaxis studies are summarized in Table 2 and the treatment studies in Table 3.

Prophylaxis: In a large European multicentre study (13) the prophylactic effect of ranitidine $150 \mathrm{mg}$ bid was compared with placebo in 297 patients taking NSAIDs for either rheumatoid arthritis or osteoarthritis. All patients had a normal endoscopy at initiation into the study. The NSAIDs were continued throughout the study. At week 4 there were significantly fewer patients with gastric-mucosal lesions (including ulcers) in the ranitidine group. This improvement was not found at week 8 . Overall duodenal mucosal lesion scores (including ulcer) were not significantly different at week 8 . At the end of the eight weeks, $6 \%$ of patients in both treatment groups had developed gastric ulcers. Two of $135(1.5 \%)$ developed duodenal ulceration in the ranitidine group compared with 10 of $126(8 \%)$ taking placebo $(\mathrm{P}=0.02)$. The cumulative incidence of peptic ulcer by eight weeks was $10.3 \%$ (27 of 263). Patients with a history of peptic ulcer appeared to be particularly susceptible to recurrent ulceration. When ranitidine was compared with placebo there was no statistical difference in the prevalence and severity of upper GI symptoms in either treatment group, both before and at the end of the treatment.

Robinson (14) studied 144 patients with NSAID)-associated gastric and duodenal lesions. After a normal endoscopy the NSAIDs were continued and patients were randomized to either ranitidine $150 \mathrm{mg}$ bid or placebo for eight weeks. The gastric and duodenal mucosa was graded on a 0 to 4 scale at the end of the study. No significant differences were found between the two study groups in the degree of gastric mucosal damage. Six of 50 patients $(12 \%)$ on placebo and six of 60 patients $(10 \%)$ on ranitidine developed a gastric ulcer. In the duodenum the degree of maximum mucosal injury was signifi- 
cantly less in the ranitidine group at both four and eight weeks ( $P>0.01$ and $\mathrm{P}=0.01)$. Four of 49 patients $(8 \%)$ on placebo and none of the 57 patients taking ranitidine developed a duodenal ulcer after eight weeks of NSAID therapy $(\mathrm{P}=0.02)$. There were no statistically significant differences between treatment groups with respect to symptoms of peptic distress or incidence of epigastric pain. There was no association between symptoms and the degree of mucosal damage by endoscopy.

Stalinkowicz (51) studied 191 patients with indomethacin-associated gastric and duodenal lesions. After a normal endoscopy all patients were commenced on indomethacin $50 \mathrm{mg}$ tid for acute musculoskeletal disorders. Patients were randomized to either cimetidine $400 \mathrm{mg}$ bid, $400 \mathrm{mg}$ at bedtime or placebo for only one week and the endoscopy was repeated. At the second endoscopy, esophageal and fundic damage were negligible. Overall, all gastric and duodenal lesion scores in all patients treated with cimetidine $400 \mathrm{mg}$ bid were significantly lower $(\mathrm{P}<0.012)$ than in placebo-treated patients. Cimetidine $400 \mathrm{mg}$ bid provided significant protection for the duodenum ( $\mathrm{P}=0.0004$ ) but protection of the antral mucosa did not reach statistical significance. Cimetidine $400 \mathrm{mg}$ at bedtime was not superior to placebo in improving mean endoscopic scores. There was no statistical difference in global symptom relief between the three treatment groups.

In a similar study with 110 patients Stalinkowicz (52) found no significant differences in the percentage of patients with gastroduodenal damage (hemorrhage, erosions, or ulceration) or in the severity of the lesions when ranitidine $150 \mathrm{mg}$ bid was compared with placebo. The percentage of subjects with gastric mucosal damage as well as the severity of the lesions were similar in the ranitidine and the placebo treatment groups. One patient in each treatment group was found to have a gastric ulcer. In the duodenum, hemorrhages were found in neither treatment group. There was no statistically significant difference between the percentage of subjects with erythema or erosions in the ranitidine and placebo group. The severity of the lesions was also similar in both treatment groups. Three patients in the ranitidine group and one in the placebo group were found to have duodenal ulcers. Ranitidine did not ameliorate indomethacininduced epigastric pain, heartburn, nausea and vomiting when compared with placebo. There was no correlation between upper GI symptoms and endoscopic findings in either of these studies. Treatment: Loludice et al (53) studied 70 patients with NSAID-associated gastric ulcers. The NSAIDs were discontinued and the patients were randomized to either cimetidine $300 \mathrm{mg}$ qid plus antacid or placebo plus antacid for six weeks. Repeat endoscopy at six weeks showed a $66 \%$ (25 of 38 patients) healing for the cimetidine group and 25\% (eight of 32) healing for the placebo group $(\mathrm{P}<0.001)$. Patients who had not healed in the cimetidine group underwent surgery whereas patients in the placebo group were crossed over to the cimetidine plus antacid treatment. By the end of the 12-week perind of cimetidine plus antacid $67 \%$ (16 of 24) of gastric ulcers had healed. Patients who had healed their gastric ulcers were restarted on an NSAII) and cimetidine $300 \mathrm{mg}$ hid plus antacid was continued for a year. During this one-year followup of 31 patients there was a $6.5 \%$ (two of 31) incidence of symptomatic recurrence. There were no data on symptoms in the six-week placebo-controlled treatment period of this study.

O'Laughlin (54) studied 18 patients with NSAID-associated gastric ulcers who were randomized to either cimetidine $300 \mathrm{mg}$ qid plus prn antacids or placebo plus prn antacids. The NSAII) therapy was continued during the study. Follow-up endoscopy at eight weeks demonstrated no significant difference $(P>0.05)$ between the two groups in healing of the gastric ulcer cimetidine plus antacids 56\% (five of nine) versus placebo plus antacids $44 \%$ (four of seven). Gastric ulcers less than $5 \mathrm{~mm}$ in diameter showed $90 \%$ healing at eight weeks whereas larger ulcers only showed a $25 \%$ healing. There was no significant difference $(\mathrm{P}>0.05)$ in relief of epigastric pain in the two treatment groups. Therapy was continued to endoscopic healing in 17 of the 18 ulcers which healed over a six - to 26 month period of therapy. The 18 th patient went to surgery.

Davies and co-workers (55) studied 27 patients ( 21 with gastric ulcers, six with duodenal ulcers) randomized to either cimetidine (400 mg qid) with antacid or placebo with antacid. The NSAII) therapy was continued. After six weeks of treatment, $85 \%$ of ulcers (nine of 14) had healed with cimetidine and $60 \%$ (six of 10 ) had healed with placebo. This difference was not statistically different $(\mathrm{P}>0.05)$. With cimetidine two of three duodenal ulcers and three of 10 gastric ulcers healed and with placebo two of three duodenal ulcers and four of seven gastric ulcers healed. There was no statistical difference in analgesic or antacid ingestion.

Roth et al (56) studied 104 patients taking NSAIDs for a variety of rheumatic diseases. All of these patients had gastric mucosal lesions (erythema and erosions) but no patients had gastric ulcers. The NSAll s were continued during the eight-week study and many patients were taking other drugs, in addition to NSAIDs, that could affect healing (eg, penicillamine, methotrexate, steroids). The NSAID dose was adjusted by the individual physicians during the study. Fifty-eight per cent of patients (22 of 43) randomized to cimetidine $300 \mathrm{mg}$ qid and $52 \%$ of those randomized to placebo (22 of 42) showed progression of endoscopic lesions during the eight-week doubleblind phase $(P>0.05)$. Thirty-nine patients whose endoscopic lesions improved were then randomized to a 10 month maintenance regimen of either cimetidine $400 \mathrm{mg}$ at bedtime or placebo. Fifty per cent of placebo-treated (seven of 14) and $42 \%$ of cimetidine treated patients (five of 12) showed progression of lesions during the maintenance phase $(\mathrm{P}>0.05)$. There were no data on symptoms in this study.

Lancaster-Smith et al (57) studied 190 patients with NSAID-associated ulcers. All patients received ranitidine $150 \mathrm{mg}$ bid and were randomized to continue or stop NSAID treatment. At eight weeks, $63 \%$ of gastric ulcers and $84 \%$ of duodenal ulcers had healed 
while the NSAID was continued. In the group which discontinued NSAIDs, 95\% of gastric ulcers and $100 \%$ of duodenal ulcers healed at eight weeks. The difference in healing rates were statistically significant for both gastric ulcers $(\mathrm{P}=0.001)$ and duodenal ulcers $(\mathrm{P}=0.006)$. At 12 weeks $79 \%$ of gastric ulcers and $92 \%$ of duodenal ulcers were healed in the group continuing NSAlDs. All patients with gastric or duodenal ulcers who stopped taking NSAII)s were healed at 12 weeks. There was no statistical difference in improvement in symptom score between the two groups.

While the $\mathrm{H}_{2}$ receptor antagonists provide effective prophylaxis for NSAID-associated damage in the duodenum, they have not demonstrated efficacy in the stomach either for prophylaxis or treatment of NSAID-associated gastric mucosal damage. This suggests that acid suppression is of greater importance for mucosal protection in the duodenum than in the stomach where mucosal defence mechanisms appear to be more important. The efficacy of omeprazole in a small number of patients in healing gastric ulcers with more total acid suppression (49) suggests that larger doses of $\mathrm{H}_{2}$ receptor antagonists might have similar efficacy in the stomach.

Side effects: The $\mathrm{H}_{2}$ receptor antagonists are safe with a low incidence of side effects. The main concern with cimetidine is its potential for drug interactions with diazepam, warfarin and phenytoin. Other side effects include diarrhea or constipation. Ranitidine has a low incidence of side effects, with the main complaint being headache. The recommended dose for treatment of ulcers with ranitidine is $150 \mathrm{mg}$ bid and with cimetidine $300 \mathrm{mg}$ qid for six to eight weeks. Ranitidine has recently been approved in Canada for the treatment of NSAID-associated lesions, GI symptoms and prevention of their recurrence.

\section{OMEPRAZOLE}

Omeprazole significantly inhibits gastric acid production by blocking the enzyme $\mathrm{H}+, \mathrm{K}+$ - ATPase in the parietal cell. Omeprazole is a more potent acid suppressor than the $\mathrm{H}_{2}$ receptor antag- onists and will significantly reduce the aggressive factors. Omeprazole has not been shown to have any effect on the defensive factors of the gastric mucosa.

In a study of 602 patients comparing omeprazole with ranitidine in the healing of benign gastric ulcers, $14.6 \%$ or 88 patients had NSAID-associated ulcers (49) (Table 3). The NSAID was continued during the study. Eighteen of these patients $(8.8 \%$ of all patients) were randomized to omeprazole $20 \mathrm{mg}$ once a day, 21 patients $(10.8 \%)$ to omeprazole $40 \mathrm{mg}$ once a day, and 19 patients $(9.2 \%)$ to ranitidine $150 \mathrm{mg}$ bid. Omeprazole $40 \mathrm{mg}$ once a day was superior to ranitidine $150 \mathrm{mg}$ bid in healing gastric ulcers $(95 \%$ versus $53 \%$ ) at both weeks 4 and 8 while the NSAIDs were continued $(\mathrm{P}=0.01)$. There were no data on symptom improvement in the subsection of patients taking NSAIDs. Overall symptom improvement was significantly superior for omeprazole at weeks 4 and 8 compared with ranitidine.

Side effects: Omeprazole has a low incidence of side effects with the main concerns being headaches, nausea, $\mathrm{di}$ arrhea or constipation. The earlier concerns about long term use of omeprazole and changes in serum gastrin and potential carcinoid-like tumours (58) have resolved with clinical experience. Omeprazole has been approved for maintenance therapy of gastroesophageal reflux disease (GERD) in the United Kingdom and this indication is under review by the HPB. The recommended dose for the treatment of gastric ulcers is 20 to $40 \mathrm{mg}$ once a day for four to eight weeks.

There are two large multicentre studies ongoing in Canada comparing omeprazole with misoprostol and ranitidine in the prophylaxis and treatment of NSAID-associated gastric and duodenal ulcers. Omeprazole is not approved for the prophylaxis or treatment of NSAID-associated symptoms or ulceration.

\section{SUCRALFATE}

Sucralfate is a sulphated polysaccharide that does not suppress acid production but exerts its effect by mucosal protection. In the presence of acid, sucralfate forms a chemical complex that binds to the ulcer site to establish a protective barrier. This appears to block the back diffusion of gastric acid and appears to have a direct inhibitory effect on the action of pepsin and bile on the gastric mucosa (59). Sucralfate has also been shown to increase the synthesis and release of prostaglandin E2 from the gastric mucosa (60). It appears that this may be due to the aluminum component of sucralfate as aluminum-containing antacids have also been shown to have similar action. More recently sucralfate has been shown to find basic fibroblast growth factor and to deliver this growth factor to the ulcer. This may be important in stimulating granulation and angiogenesis in the ulcer bed (64). Sucralfate has been shown to be protective to the gastric mucosa in the acute administration of ASA (61). However, in the longer duration studies of six days and two weeks sucralfate did not protect the gastric mucosa against ASA $(62,63)$.

There have only been two controlled published studies on the efficacy of sucralfate in the treatment of NSAID. associated mucosal damage and ulceration (Table 3). There have been no prophylaxis studies with sucralfate.

Manniche et al (65) carried out a randomized single blind study in $60 \mathrm{pa}-$ tients with ulcers $(51$ with duodenal ulcers, 14 with gastric ulcers, and two with both) in patients taking NSAIDs. The NSAIDs were continued in half the patients and stopped in the others. $\mathrm{Pa}$ tients who had not healed at nine weeks on the initial therapy were crossed over to the other drug and treated for another three- to nine-week period. The mean healing time in 27 patients given ranitidine $(150 \mathrm{mg}$ bid) was 4.9 weeks and 25 patients given sucralfate $(1 \mathrm{~g}$ qid) was 4.6 weeks. The overall healing rate for all ulcers for ranitidine was $84 \%$ (27 of 32 ) and sucralfate was $85 \%$ ( 25 of 30 ). In the 10 patients with unhealed ulcers, after the initial nine weeks of treatment healing was achieved in seven of 10 after further therapy for three to 9 weeks. Ninety-one per cent of ulcers healed with the NSAlDs stopped and $77 \%$ healed with continued NSAII therapy. 
The majority of patients $(75 \%)$ in this study had duodenal ulcers. In the 14 patients with gastric ulcers, $86 \%$ (six of seven) healed with the NSAIDs stopped and only $50 \%$ (three of six) healed when the NSAID was continued. There were no data on symptoms in this study.

In the other study with sucralfate, Caldwell studied 143 patients on long term NSAIDs with mucosal damage (50). The 60 patients with gastric ulcers or erosions (number of ulcers was not specified) were randomized either to sucralfate $1 \mathrm{~g}$ yid or placebo with the NSAID being continued. Lesion score improvements were not significantly different after four weeks of treatment when sucralfate was compared with placebo. The mean lesion score change within each treatment group was unchanged in the placebo group and showed only a small change (3.5 to 2.46) in those given sucralfate $(\mathrm{P}<0.005)$. Sucralfate was effective in decreasing symptoms when compared with placebo in those patients taking long half life or non-acetylated NSAIDs. Patients taking acetylated or short halt life NSAIDs did not benefit. There was a significant decrease in intensity but not frequency of symptoms for all NSAII)s. Whether or not the evidence of mucosal damage effected the symptom outcome was not stated.

Side effects: Sucralfate is a nonsystemic drug which has a low incidence of side effects. The most common complaint with sucralfate is constipation. It has also been shown to decrease the absorption of a variety of drugs including tetracycline, phenytoin, cimetidine and digoxin. Studies have demonstrated raised serum aluminum levels in patients taking therapeutic doses of sucralfate (66). Whether or not this is important in Alzheimer's disease remains to be defined. The recommended dosage for acid-mediated ulcers is $1 \mathrm{~g}$ qid (before meals and at bedtime). Sucralfate is not approved for the prophylaxis or treatment of NSAID-associated symptoms or ulceration.

\section{MISOPROSTOL}

Misoprostol is a synthetic methyl esther analog of prostaglandin $E_{1}$, which has been shown to have both acid antisecretory effects (67) and mucosal protective effects (68). The mucosal protective effects of the prostaglandins are the result of increasing mucus and bicarbonate secretion which results in an increase in the thickness of the mucus layer. Misoprostol has also been shown not to decrease gastric mucosal bloodflow, which is thought to be important for cell integrity. This action is found in the $E_{1}$ and $\mathrm{E}_{2}$ prostaglandins. Another prostaglandin $\mathrm{E}_{1}$ analogue, enprostil (Syntex), has undergone clinical trials (69). This article will focus on misoprostol, which is the only prostaglandin approved in Canada at this time.

There have been five placebo-controlled studies with misoprostol in patients taking NSAIDs. There has also been one study where misoprostol was compared with sucralfate in preventing NSAID-associated gastric ulcers.

Prophylaxis: Ryan looked at the effect of misoprotol in preventing Gl blood loss produced by ASA in patients with degenerative bone disease (70). Fortyfive arthritic patients taking $3900 \mathrm{mg}$ of ASA per day in four divided doses were studied. Red hlood cells were tagged with chromium 51 and fecal blood loss was determined at baseline and on days 4 to 7. Patients with a mean blood loss of at least $1.5 \mathrm{~mL}$ per day were randomly allocated to misoprostol $200 \mu \mathrm{g}$ qid or placebo for seven days. In 19 patients who were treated with misoprostol, 11 $(57.9 \%)$ had at least a $50 \%$ reduction in blood loss $(\mathrm{P}=0.003)$. The mean blood loss was significantly reduced in the misoprostol group whereas it did not significantly change in those patients taking placebo $(\mathrm{P}=0.0023)$.

In a large double-blind placebo controlled study (46) 420 patients with osteoarthritis, abdominal pain and receiving either ibuprofen piroxicam or naproxen were studied (Table 2). All patients were required to have $\mathrm{Gl}$ pain but no ulcer. When patients were screened $25 \%$ of patients were found to have gastric ulcers and were therefore excluded. Patients were randomized to either misoprostol $100 \mu \mathrm{g}$ qid, $200 \mu \mathrm{g}$ qid or placebo. Endoscopy was performed at entry and at one, two, and three months. At the end of the three months, $21.7 \%$ in the placebo group, $5.6 \%$ of patients taking $100 \mu \mathrm{g}$ miseprostol $(\mathrm{P}<0.001)$ and $1.4 \%$ taking $200 \mu \mathrm{g}$ misoprostol $(\mathrm{P}<0.001)$ developed gastric ulcers (greater than 0.3 $\mathrm{cm})$. The significant difference in ulcer formation between placebo and the misoprostol treatment groups remained when comparisons were restricted to an ulcer greater than $0.5 \mathrm{~cm}$ in diameter. NSAID-associated abdominal pain was rated by both the patient and physician. By the end of the three months of therapy $56.6 \%$ of patients taking placebo, $75.4 \%$ of patients taking misoprostol $100 \mu \mathrm{g}$ and $70.7 \%$ of patients taking $200 \mu \mathrm{g}$ misoprostol were pain free. These differences were not statistically significant. The same protocol (Table 2) was repeated by Graham et al (71) where he compared misoprostol $200 \mathrm{mg}$ gid to placebo in patients taking NSAIIs in preventing duodenal ulcers (larger than $0.5 \mathrm{~cm}$ diameter). After three months duodenal ulcers developed in two of the 320 patients $(0.6 \%)$ randomized to receive misoprostol compared with 15 of the 323 patients $(4.6 \%)$ receiving placebo $(\mathrm{P}=0.002)$. Gastric ulcers also developed in six of the $320(1.9 \%)$ treated with misoprostol and 25 of the 323 $(7.7 \%)$ treated with placebo $(\mathrm{P}=0.001)$. There was no significant difference in the results when a subset analysis was performed for a previous history of pep. tic ulcer disease. There was no statistically significant improvement in symptoms at weeks 6 or 12 between the two treatment groups in assessments of daytime and nighttime pain regardless of baseline ratings.

Misoprostol has also been compared with sucralfate with respect to their efficacy as prophylaxis therapy to prevent gastric ulcers in patients taking NSAIDs (72) (Table 2). Two hundred and fiftythree patients with osteoarthritis and no ulceration on endoscopy were randomized to either misoprostol $(200 \mu \mathrm{g}$ qid) or sucralfate $(1 \mathrm{~g}$ qid) in this controlled single-blind study. The NSAII was continued throughout the study. Endoscopy was repeated at one, two and three months. At the end of the three months two of 122 patients $(1.6 \%)$ taking misoprostol had devel. 


\section{TABLE 4}

\section{The patient at highest risk of devel- oping NSAID-associated GI compli- cations}

Age more than 60 years

Previous history of peptic ulcer disease

Major other medical diseases

(co-morbidity)

Large doses of NSAIDs

Combination of NSAIDS

Co-therapy with steroids

Gl Gastrointestinal; NSAIDs Nonsteroidal antiinflammatory drugs.

oped a gastric ulcer (larger than $0.3 \mathrm{~cm}$ diameter) compared with 21 of 131 patients $(16 \%)$ taking sucralfate $(\mathrm{P}=0.001)$.

Recently, misoprostol with enteric coated diclofenac has been marketed as a combination capsule. To date the preliminary data for up to 24 weeks have only been published comparing diclofenac and misoprostol with diclofenac and placebo in an endoscopically controlled prophylactic study in patients with rheumatoid arthritis or osteoarthritis for 52 weeks. (Table 2). A total of 142 patients completed 12 weeks and 114 completed 24 weeks of this 52-week study. Endoscopy before entry had demonstrated no significant lesions. The misoprostol and diclofenac combination was statistically superior in preventing clinically significant gastroduodenal lesions $(\mathrm{P}<0.02)$. The difference was also sig. nificant when duodenal $(\mathrm{P}=0.0092)$ but not gastric $(P=0.175)$ were considered separately (73).

Treatment: In a multicentre treatment study (74) patients with rheumatoid arthritis and ASA-associated mucosal damage were randomized to either misoprostol $200 \mu \mathrm{g}$ qid or placebo (Table 3). The therapeutic doses of ASA were continued throughout the eight-week study. Endoscopy was performed at baseline and at four and eight weeks. A therapeutic success was defined as a clinically significant improvement in global endoscopic grades. Patients with more severe lesions (erosions and $\mathrm{ul}$ cers) only had to improve one grade whereas patients with milder lesions (hemorrhagic lesions, erythema) had to improve two grades. After eight weeks of treatment misoprostol was statistically superior to placebo in healing gastric mucosal injury ( $70 \%$ versus $25 \%$ ) $(\mathrm{P}<0.001)$ and duodenal mucosal injury $(86 \%$ versus $53 \%)(P<0.001)$. Separate analysis of gastric and duodenal ulcer healing were also performed. Twentynine patients in the misoprostol group and 28 in the placebo group had a gastric ulcer. Eighteen $(62 \%)$ and eight $(32 \%)$, respectively, were healed at week $8(P=0.02)$. Eighteen patients had duodenal ulcers at the outset $(10$ misoprostol, eight placebo). The misoprostol healing rate was numerically superior to placebo ( $90 \%$ versus $50 \%$ ) but the sample size was too small for statistical difference. The overall ulcer healing rate was statistically significant $(67 \%$ versus $26 \%)(\mathrm{P}=0.0006)$. There was no significant improvement in upper GI pain between the two treatment groups.

Walt (75) recently critically reviewed the role of misoprostol in the prophylaxis and treatment of NSAIDassociated mucosal damage. His conclusion was that routine clinical prophylaxis with misoprostol in patients taking NSAIDs was not yet justified. His views are not those reflected by Langman's working party report to the World Congress of Gastroenterology in Sydney in 1990 (15). Walt based this recommendation on the lack of end point data and also that misoprostol prevented endoscopic ulcers and not clinical ulcers. Although misoprostol has been shown to effectively prevent ulcers for up to three months in both the stomach and duodenum $(46,71)$, it has not been shown to prevent serious complications such as bleeding, perforation or death. Walt based his review on the unproven supposition that serious complications result from clinical ulcers not endoscopic ulcers. Walt felt that the ulcers studied by Graham were acute endoscopic ulcers which do not cause serious complications. A much longer study with a longer patient group is needed to study differences in complications and mortality rates. No study has addressed prevention of complications with NSAIDS with any of the therapeutic agents. Furthermore, there is a paucity of data demonstrating efficacy of any drug in preventing ulcer complications in maintenance therapy for acid-mediated ulcer disease. There is presently a large end point study underway in the United States which is enrolling 10,000 patients to measure the effects of misoprostol compared with placebo on mortality and complications in patients taking NSAIDs over a one-year period. In the United Kingdom there is also a large four-year end point study being analyzed. These studies should resolve the controversy as to whether maintenance prophylaxis therapy reduces complications.

Gabriel has looked at the cost effec. tiveness for misoprostol for NSAID-associated GI events. In the Canadian health care setting, Gabriel felt that misoprostol prophylaxis may be highly cost effective if prophylaxis was for elderly (older than 60 years) NSAID users. In this group the prophylactic cost of misoprostol was $\$ 650$ for every additional GI event prevented. This meant that prophylactic therapy was cost saving in elderly patients where the ulcer complication rate exceeded $1.2 \%$, the charges for out-patient ulcer treatment exceeded $\$ 2000$ or the three-month price of misoprostol was less than $\$ 90$ (76). Gabriel re-evaluated her analysis following Walt's critical review of misoprostol (75). It was the opinion of the authors that their explicit conservative approach based on a meta-analysis of 16 studies (24) was a more credible analysis.

Side effects: Diarrhea and cramping occur in approximately $11 \%$ of patients starting misoprostol. This incidence has been reported to be as high as 39\% (46). The diarrhea and cramping appear to be dose related and can be minimized by taking the medication with food and normally resolves within five to seven days. Abdominal pain occurred in 13 to $20 \%$ of patients in the NSAID trials and about $7 \%$ in all studies with misoprostol. Other side effects include gynecological complaints with an incidence of less than $1 \%$. The recommended dose of misoprostol is 400 to $800 \mu \mathrm{g}$ a day for the prophylaxis and treatment of NSAID-associated gastric ulcers. 


\section{COMPARATIVE STUDIES}

There has only been one study comparing the mucosal protective effect of misoprostol with cimetidine (77). This seven-day double-blind placebo controlled study demonstrated that misoprostol prevented tolmetin-induced gastroduodenal injury in $93.1 \%$ of healthy subjects $(\mathrm{P}<0.001$ compared with placebo) compared with $63 \%$ for cimetidine $(\mathrm{P}=0.004$ compared with placebo) and $26.7 \%$ for placebo. Misoprostol was also superior $(\mathrm{P}=0.006)$ when compared with cimetidine in preventing mucosal damage. Separate analysis of the gastric scores revealed success rates identical to the overall evaluation. Both misoprostol and cimetidine were highly protective compared with placebo in the duodenum.

In a single-blind study on the effect of the prevention of ASA-induced ulceration (62), 30 healthy volunteers with endoscopically normal mucosa were randomized to receive ASA 650 mg qid with either misoprostol $200 \mu \mathrm{g}$ qid, sucralfate $1 \mathrm{~g}$ qid or placebo for seven days. A prophylactic success was defined as less than 10 hemorrhages or erosions. All patients on misoprostol were deemed a success (10 of 10), 20\% on sucralfate (two of 10 ) and $0 \%$ of patients $(0$ of 10$)$ on placebo. Misoprostol was significantly superior when compared with placebo and with sucralfate $(\mathrm{P}=0.001)$.

In clinical studies misoprostol was superior to sucralfate in preventing gastric ulcers in patients taking NSAIDs for osteoarthritis (72). Both ranitidine and sucralfate appeared to be equally effective in treating NSAID-associated duodenal ulcers whether or not the NSAID was discontinued (65). These studies are described in detail elsewhere in this article.

\section{SUMMARY OF CLINICAL TRIALS}

$\mathrm{H}_{2}$ receptor antagonists: The $\mathrm{H}_{2}$ receptor antagonists cimetidine and ranitidine have not been shown to improve NSAID-associated GI symptoms compared with placebo. They have no proven benefit in the prophylaxis and treatment of NSAID-associated gastric ulcers. Ranitidine and cimetidine have been shown to be effective in the pro- phylaxis against NSAID-associated duodenal ulcer disease. Their exact role in the treatment of NSAID-associated duodenal ulcer disease remains to be defined. The dosages used in these clinical studies were cimetidine $300 \mathrm{mg}$ qid and ranitidine $150 \mathrm{mg}$ bid.

Omeprazole: In a small number of patients, omeprazole (40 mg once a day) was superior to ranitidine $(150 \mathrm{mg}$ bid) in healing NSAII)-associated gastric ulcers while the NSAII was continued. Studies are ongoing looking at omeprazole in the prophylaxis and treatment of NSAID-associated ulcers.

Sucralfate: Sucralfate was effective in improving symptoms compared with placebo for the milder NSAII)s. Sucralfate has not been shown to be effective in improving NSAlI)-associated gastric damage compared with placebo. Sucralfate was as effective as ranitidine in healing NSAID-associated duodenal ulcers whether or not the NSAID was continued. The recommended dose of sucralfate is $1 \mathrm{~g} 30 \mathrm{mins}$ before meals and at bedtime.

Misoprostol: Misoprostol has not been shown to improve symptoms compared with placebo. Misoprostol was effective prophylactic therapy against NSAIDassociated gastric ulcers at a dose of either $100 \mathrm{mg}$ qid or $200 \mathrm{mg}$ qid. Misoprostol (200 mg qid) was also superior to sucralfate $(1 \mathrm{~g}$ qid) in preventing NSAID-associated gastric ulcer. Misoprostol (200 mg qid) has also been shown to be an effective prophylactic therapy against NSAID-associated duodenal ulcer. Misoprostol has been shown to be effective in healing NSAID-associated gastric ulceration while the NSAID (ASA) was continued. Its exact role in the treatment of NSAID-associated duodenal ulcer disease remains to be defined. The recommended dose of misoprostol is 400 to $800 \mu \mathrm{g}$ per day in divided doses with meals and at bedtime.

\section{CONCLUSIONS}

The patient at risk and prophylaxis therapy: This issue is reviewed in detail elsewhere in this publication. There is no question that the use of prophylaxis therapy in patients taking NSAIDs is controversial. It is up to the individual physician to define which patients are at the highest risk and to decide whether to use prophylaxis therapy to try and reduce the morbidity and mortality associated with NSAIDs reviewed in this article. Alternatively one may decide to wait for more clearly defined end point data on preventing complications with prophylactic therapy. Table 4 summarizes a personal interpretation of the literature to try and define the high risk patient that one should consider for prophylaxis against NSAll?. associated GI complications. The therapeutic agent used in prophylaxis should be based on a critical review of this literature and ideally protect both the gastric and duodenal mucosa.

Treatment of symptoms: In patients with symptoms (bearing in mind there is no correlation between symptoms and ulceration), one may consider reducing the dose or trying an alternative NSAID which is often effective. Antacids which are nonsystemic and safe have not been shown to be effective but will have a good placebo response. Both sucralfate and misoprostol have been shown to have some efficacy in improving symptoms in patients taking NSAIDs and either of these medications could be considered.

Treatment of erosions and/or ulceration: In the patient with documented erosions or ulceration one has to reevaluate the necessity for the NSAID, If the NSAID is to be continued then misoprostol appears to be the most effective therapy in healing NSAID-associated gastric ulceration and mucosal damage. These patients will need to be followed closely with follow-up endoscopy in four to eight weeks. Omeprazole in a small number of patients healed NSAID-associated gastric ulcers and may also play a role if future studies confirm this efficacy. For NSAID-associated duodenal ulcers both ranitidine and sucralfate have demonstrated some efficacy in healing duodenal ulcers while the NSAID is continued. If acid is an important component in NSAIDassociated duodenal ulcers, then one would anticipate omeprazole having similar or better efficacy than ranitidine.

If the NSAID can be discontinued then any conventional treatment for the ulcer can be prescribed. 
ACKNOWLEDGMENT: I gratefully acknowledge Anna Micueci for her secretarial assistance in preparing this manuscript.

\section{REFERENCES}

1. Lee P, Helewa A, Smythe HA, Bombardier C, Goldsmith CH. Epidemiology of musculoskeletal disorders and related disurders in Canada. I Rheumatol 1985:12:1169-73.

2. FDA Bimonthly Update. Pharmacy Times. United States Department of Health \& Human Services 1989;118-20.

3. Mclnterh JH, Byth K, Piper DW. Environmental factors in etiology of chronic gastric ulcer: A case control study of exposure variables before the first symptoms. Gut 1985:26:789-98.

4. Duggan IM, Dohson J, Johnson $\mathrm{H}$. Fahey P. Peptic ulcer and non-steroidal anti-inflammatory agents. Gut 1986;27:929-33.

5. Eliakim R, Ophir M, Rachmilewitz D. Duodenal mucosal injury with nonsteroidal anti-inflammatory drugs. J Clin Gastroenterol 1987;9:395-9.

6. Graham DY, Smith IL Gastroduodenal complications of chronic NSAID therapy. Am J Gistroenterol 1988:83:1081-4.

7. Lanza FL, Royer GL, Neloon RS, et al. The effects of ibuprofen. indomethacin, aspirin, naproxen, and placebo on the gastric mucosa of normal volunteers: A gastroscopic and photographic study. Dig Dis Sci 1979;24:823-8.

8. Hansen TM, Matzen P, Madsen P Endoscopic evaluation of the effect of indomethacin capsules and suppositories on the gastric mucosa in rheumatic patients. J Rheumatol 1984:11:484-7.

9. Carson IL, Strom BL, Morse M-L. et al. The relative gastrointestinal toxicity of the non-steroidal anti-inflammatory drugs. Arch Intern Med 1987:147:1054-9

10. McCarthy DM. Nonsteroidal anti-inflammatory drug-induced ulcers: Management by traditional therapies. Gastroenterology 198;96:662-74.

11. Bjarson I, Zanelli G, Prouse P, et al. Nonsteroidal anti-inflammatory drug induced intestinal inflammation in humans. Gastroenterology 1987:93:480-9.

12. Allison MC, Howatson AG, Torrance CI, Lee FD, Russell RI. Gastrointestinal damage associated with the use of nonsteroidal anti-inflammatory drugs. N Engl J Med 1992;327:749-54.

13. Ehsanullah RSB, Page MC, Tildesley G. Wood JR. Prevention of gastroducedenal damage induced by non-steroidal anti-inflammatory drugs:
Controlled trial of ranitidine. Br Med J 1988;297:1017-21.

14. Rohinson MG, Griffith JW, Bowers J, et al. Effect of ranitidine on duodenal mucosal damage induced by nonsteroidal anti-inflammatory drugs. Dig Dis Sci 1989; 34:424-8.

15. Langman MIS, Brooks P, Hawkey CJ, Silverstein F, Yeomans N. Working Party Report to the World Congress of Gastroenterology, Sydney, 1990. Non-steroidal anti-inflammatory drug associated ulcer: Epidemiology, causation and treatment. J Gastroenterol Hepatol 1991;6:442-9.

16. Larkai EN, Smith JL, Lidsky MD, Graham DY. Gastroduodenal mucosa and dyspeptic symptoms in arthritic patients during chronic non-steroidal anti-inflammatory drug use. Am J Gastroenterol 1987;82:1153-8.

17. Adverse Drug Reactions. Ottawa: Health Protection Branch, Health and Welfare Canada.

18. Rossi AC, Hsu JP, Faich GA Ulcerogenicity of piroxicam: An analysis of spontaneously reported data. Br Med J 1987;294:147-50.

19. Langman MJS. Epidemiologic evidence on the association between peptic ulceration and antiinflammatory drug use. Gastroenterology 1989;96:640-6.

20. Lingman MJS. Ulcer complications and nonsteroidal anti-inflammatory drugs. Am I Med 1988;84(Suppl 2A):15-9.

21. Griffin MR, Ray WA, Schatfner W. Non-steroidal anti-intlammatory drug use and death from peptic ulcer in elderly persons. Ann Intern Med 1988;109:359-63.

22. Griffin MR, Piper JM, Daugherty JR, Snowden M, Ray WA. Nonsteroidal anti-inflammatory drug use and increased risk of peptic uleer disease in edderly persons. Ann Intern Med 1991:114:257-63

23. Kurata JH, Abbey DE. The effect of chronic aspirin use on duodenal and gastric ulcer hospitalizations, J Clin Gastroenterol 1990:12;260-6.

24. Gabriel SE, Jaakkimainen L. Bombardier C. Risk for serious gastrointestinal complications related to) use of nonsteroidal antiinflammatory drugs. A meta-analysis. Ann Intern Med 1991:1 15;787-96.

25. Fries IF, Williams MA, Bloch DA. Michel BA. Nonsteroidal anti-inflammatory drug-associated gastropathy: Incidence and risk factor models. Am J Med 1991;91:213-22.

26. Fries IF, Miller SR, Spitz PW, Williams CA, Huhert HB, Bloch DA Toward an cpidemiology of gastropathy associated with nonsteroidal anti-inflammatory drug use. Gastroenterology 1989:VOL $: 647-55$

27. Federal Registry, 22nd Meeting of the Arthritis Advisory Committee of the US Food and Drug Administration. Rockville, May 16, 1988.

28. Koelz HR, Fimmel CJ, Garner A, Mendlein JD, Muller-Lissner SA. The stomach and duodenum. In: Kern F Jr, Blum AL. The Gastroenterology Annual. Amsterdam: Elsevier, 1986:28-106.

29. Weir DG. New drugs. Peptic ulceration. Br Med J 1988;296:195-200.

30. Debas HT, Mulholland MW. Drug therapy in peptic ulcer discase. Curr Prob Surg 1989;xxvi:9-54.

31. Kolbasa KP, Lancaster C, Olafsson AS, Gilbertson SK. Rohert A Indomethicin-induced gastric antral ulcers in hampsters. Gastroenterology 1988;95:932-4.

32. Szabo SZ. Pharmacologic approaches and pathogenic basis for NSAID gastropathy: Prevention and treatment. Pract Gastoenterol 1991;15:30-43.

33. Wallace IL, Keenan CM, Granger N. Gastric ulceration induced by nonsteroidal anti-inflammatory drugs is a neutrophil-dependent process. Am I Physiol 1990;259:0462-7.

34. Wallace IL, Arfors KI, McKnight GW. A monoclonal antibody against the CD 18 leukocyte adhesion molecule prevents indomethacin-induced gastric damage in the rabbit. Gastroenterology 1991;100:878-83.

35. Vaananen P, Meedings JB, Wallace JL. Role of reactive oxygen metabolites in experimental NSAID gastropathy. Gastronterology 1991;100:1846. (Ahst)

36. Levi S, Goodlad RA, Lee CY, et al. Inhibitory effect of nonsteroidal antiinflammtory drugs on mucosal cell proliferation associated with gastric ulcer healing. Lancet 1990;336:840-3

37. Schoen RT, Vender RJ. Mechanisms of nonsteroidal anti-inflammatory drug-induced gastric damage. Am J Med 1989:86:449-58.

38. Roth SH, Bennett RE. Nonsteroidal anti-inflammatory drug gastropathy. Recognition and response. Arch Intern Med 1987:147:2093-100.

39. Loeb DS, Talley NJ, Ahlquist DA. Carpenter HA, Zinsmeister AR. Long-term nonsteroidal anti-inflammatory drug use and gastroduodenal injury: The role of Helicobacter pyloni. Gastroenterology 1992:102:1899-905.

40. Jones STM, Clague RB, Eldridge J. Jones DM. Serological evidence of infection with Helicobacter pylomi may predict gastrointestinal intolerance to nonsteroidal anti-inflammatery drug 
(NSAID) treatment in theumatoid arthritis. Br I Rheumatol 1991:30:16-20.

41. Graham DY, Lidsky MD, Cox AM, et al. Long-term nonsteroidal anti-inflammatory drug use and Helicobacter pylomi infection. Gastroenterology 1991;100:1653-7.

42. Robert A, Lancaster C. Gilbertson-Beadland S, et al. Gastric adaptation to ethanol-induced mucosal necrosis by daily administration of either aspirin or 100\% ethanol. Gastroenterology 1990;98:A112.

43. Graham DY, Smith IL, Downs SM. Gastric adaptation occurs with aspirin administration in man. Dig Dis Sci 1983;28:1-6.

44. Muller P, Danmann HG, Marinis B, et al. Endoscopic evaluation of gastroduodenal tolerability of low dose aspirin therapy. Gastroenterology 1990;98:A92

45. Leonards JR, Levy G. Nirmczunar J. Gastrointestinal hlood loss during prolonged aspirin administration. N Engl] Med 1973:289;1020-2.

46. Graham DY, Agrawal NM, Roth SH. Prevention of NSAID-induced gastric ulcer with misoprostol: Multicentre, double-blind, placebo-controlled trial. Lancet 1988;332:1277-80.

47. Armstrong CP, Blower AL Non-steroidal anti-inflammatory drugs and life threatening complications of peptic ulceration. Gut 1987;28:527-32.

48. Skander MP, Ryan FP. Non-steroidal anti-inflammatory drugs and pain free peptic ulceration in the elderly. $\mathrm{Br}$ Med I 1988;297:833-4.

49. Walan A, Bader J-P, Classen M, et al. Effect of omeprazole and ranitidine on ulcer healing and relapse rates in patients with benign gastric ulcer. N Engl J Med 1989;320;69-75.

50. Caldwell JR, Roth SH, Wu WC, et al. Sucralfate treatment of nonsteroidal anti-inflammatory drug-induced gastrointestinal symptoms and mucosal damage. Am J Med 1987;83(Suppl 3B): $74-82$.

51. Stalinkowicz R, Pollak D, Eliakim A. et al. Cimeridine decreases indomethacin induced duodenal mucosal damage in patients with acute musculoskeletal disorders. Gut 1988;29:1578-82.

52. Stalinkowicz R, Goldin E, Fich A, et al. Indomethacin-induced gastroduodenal damage is not affected by cotreatment with ranitidine. I Clin Gastroenterol 1989;11:178-82.

53. Loludice TA, Saleem T, Lang JA. Cimetidine in the treatment of gastric ulcer induced by steroidal and nonsteroidal anti-inflammatory agents. Am J Gastroenterol 1981;75:104-10. 54. O'Laughlin JC, Silvoso GK, lvey KJ.
Resistance to medical therapy of gastric ulcers in theumatic disease patients taking aspirin. A double-blind study with cimetidine and follow-up. Dig Dis Sci 1982;27:976-80.

55. Davies J, Collins A], Dixon A St J. The influence of cimetidine on peptic ulcer in patients with arthritis taking anti-inflammatory drugs. Br ] Rheumatol 1986:25:54-8.

56. Roth SH, Bennet RE, Mitchell CS, Hartman RJ. Cimetidine therapy in nonsteroidal anti-inflammatory drug gastropathy. Double-blind long-term evaluation. Arch Intern Med 1987;147:1798-801.

57. Lancaster-Smith MI, Jakerberg ME, Jacson DA. Ranitidine in the treatment of non-steroidal anti-inflammatory drugs. $\mathrm{Br}]$ Rheumatol 1986:25:54-8.

58. Hakanson R, Sundler F, Carlsson E, Mattsson H, Larsson H. Proliferation of enterchromaffin-like cells in the rat stomach following omeprazole treatment. Hepatogastroenterolugy $1985 ; 32: 48-9$.

59. Nagashimar R. Mechanism of action of sucralfate. J Clin Gastroenterol 1981;3(Suppl 2);117-27.

60. Konturek SJ, Kwiecien N, Obtulowicz W, Kopp B, Oloksy ]. Double-blind controlled study on the effect of sucralfate on gastric prostaglandin formation and microbleeding in normal and aspirin-treated man. Gut 1986;27:1450-6.

61. Stern AI, Ward F, Hartley G. Protective effect of sucralfate against aspirin-induced damage to the human gastric mucosa. Am l Med 1987:83(Suppl 3B);83-5.

62. Stern Al, Ward F, Sievert W. Lack of gastric mucosal protection by sucralfate during long-term aspirin ingestion in humans. Am I Med 1989:86(Suppl 6A):66-9.

63. Lanza F, Peace K, Gustitus L, Rack MF, Dickson B. A blinded endoscopic comparative study of misoprostol versus sucralfate and placebo in the prevention of aspirin-induced gastric and duodenal ulceration. Am I Gastroenterol 1988;83:143-6.

64. Szabo S, Vattay P, Scarborough E, Folkman J. Role of vascular factors, including angiogenesis, in the mechanisms of action of sucralfate. Am J Med 1991;91:150S.

65. Manniche C, Malchow-Moller A, Anderson JR, et al. Randomized study of the influence of non-steroidal anti-inflammatory drugs on the treatment of peptic ulcer in patients with rheumatic diseases. Gut 1987:28:226-9.

66. Pai S, Melethil S, Cuddy P, Hall T.
Elevation of serum aluminum in humans on a two-day sucralfate regimen. I Clin Pharmacsl 1987:27:213-5.

67. Dajani EZ. Perspective on the gastric antisecretory effects of misoprostol in man. Prostaglandins

1987;33(Suppl) :68-77

68. Daiani EZ. Overview of the mucosal protective effects of misoprostol in man. Prostaglandins 1987;33(Suppl):117-29

69. Lauritsen K, Laursen L.S, Havelund T, Bytzer P, Svendsen LB, Risk-Madsen J. Enprostil and ranitidine in duodenal ulcer healding: Double-blind comparative trial. Br J Med 1986;992:864-6

70. Ryan JR, Vargas R, Clay GA, McMahon FG. Role of misoprostol in reducing aspirin-induced gastro-intestinal hlood loss in arthritic patients. Am / Med 1987;83(Suppl 1A):41-4.

71. Graham DY, White RH, Moreland LW, et al. Duodenal and gastric ulcers in arthritis patients taking NSAID): Risk factors for ulceration and ulcer prevention with misoprostol. Ann Intern Med. (In press)

72. Agrawal NM, Roth S, Graham 1)Y, et al. Misoprostol compared with sucralfate in the prevention of nonsteroidal anti-inflammatory drug-induced gastric ulcer. A randomized, controlled trial. Ann Intern Med 1991;115:195-200.

73. Geis GS, Stead H, Wallemark CB, Nicholson PA. Prevalence of mucosal lesions in the stomach and duodenum due to chronic use of NSAID in patients with rheumatoid arthritis or osteoarthritis, and interim report on prevention by misoprostol of diclofenac associated lesions. J Rheumatol 1991;(Suppl 28)18:11-4.

74. Roth S, Agrawal N, Mahowald M, et al. Misoprostol heals gastroduodenal injury in patients with rheumatoid arthrit is receiving aspirin. Arch Intern Med 1989;1949:775-9.

75. Walt RP. Misoprostol for the treatment of pepric ulcer and anti-inflammatory drug-induced gastroduodenal ulceration. N Engl ] Med 1992;327:1575-80.

76. Gabriel SE, Jaakkimainen RL, Bombardier C. The cost-effectiveness of misoprostol for non-steroidal anti-inflammatory drug-associated adverse gastrointestinal events. Arthritis Rheum 1993;36:447-59.

77. Lanza FL, Aspinall RL, Swabb EA, Davis RE, Rack MF, Rubin A. Double-blind, placebo-controlled endoscopic comparison of the mucosal protective effects of misoprostol versus cimetidine on tolmetin-induced mucosal injury to the stomach and duodenum. Gastroenterology 1988;95:289-94. 


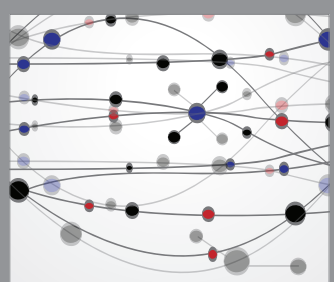

The Scientific World Journal
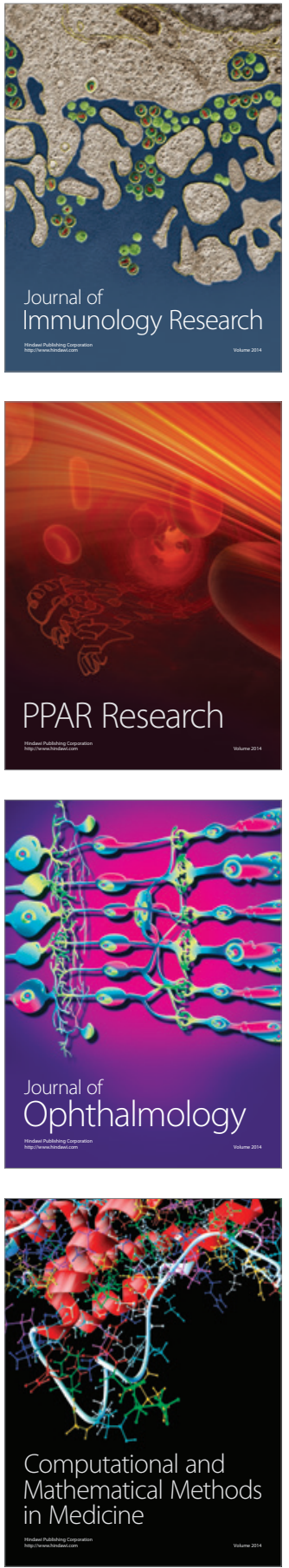

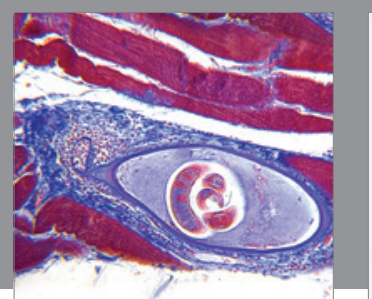

Gastroenterology Research and Practice

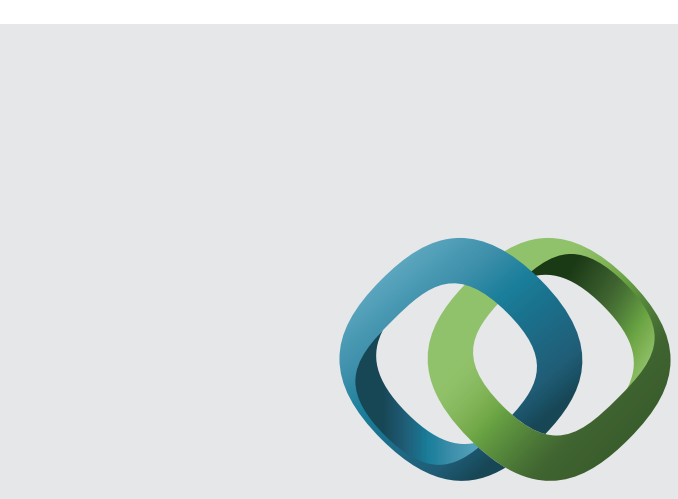

\section{Hindawi}

Submit your manuscripts at

http://www.hindawi.com
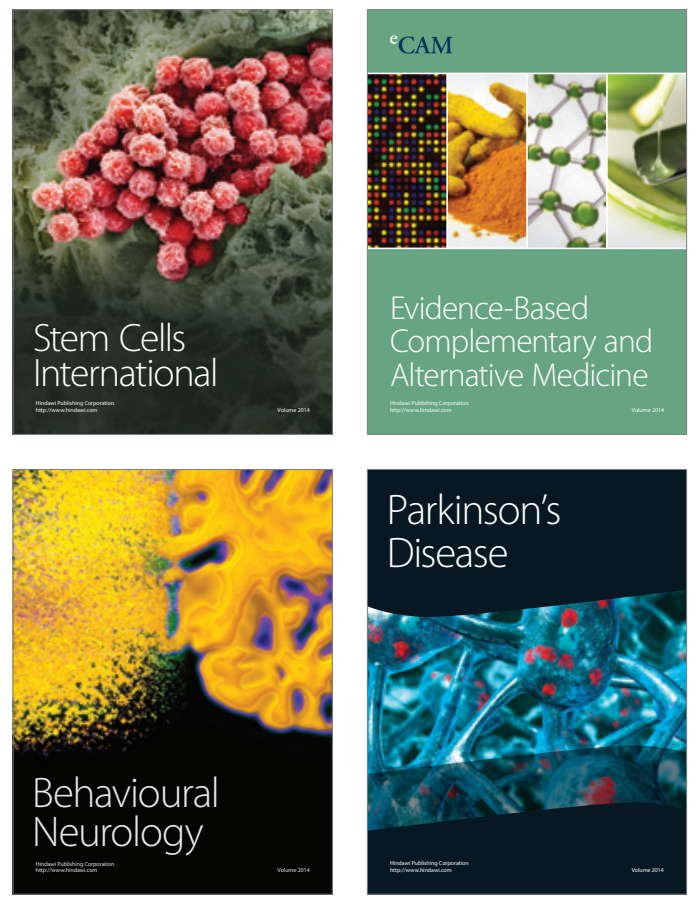
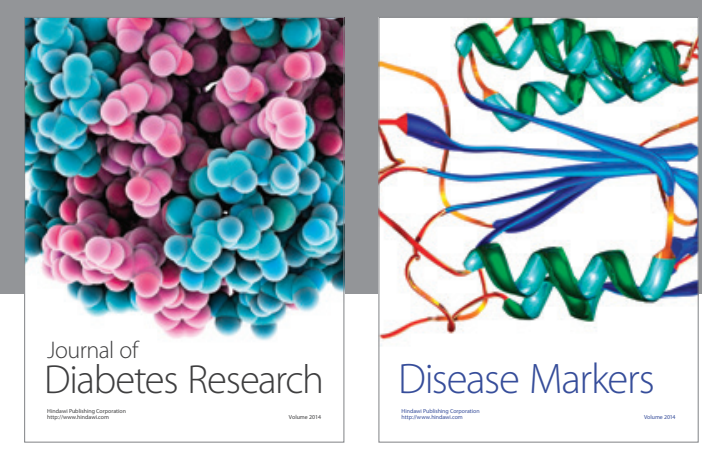

Disease Markers
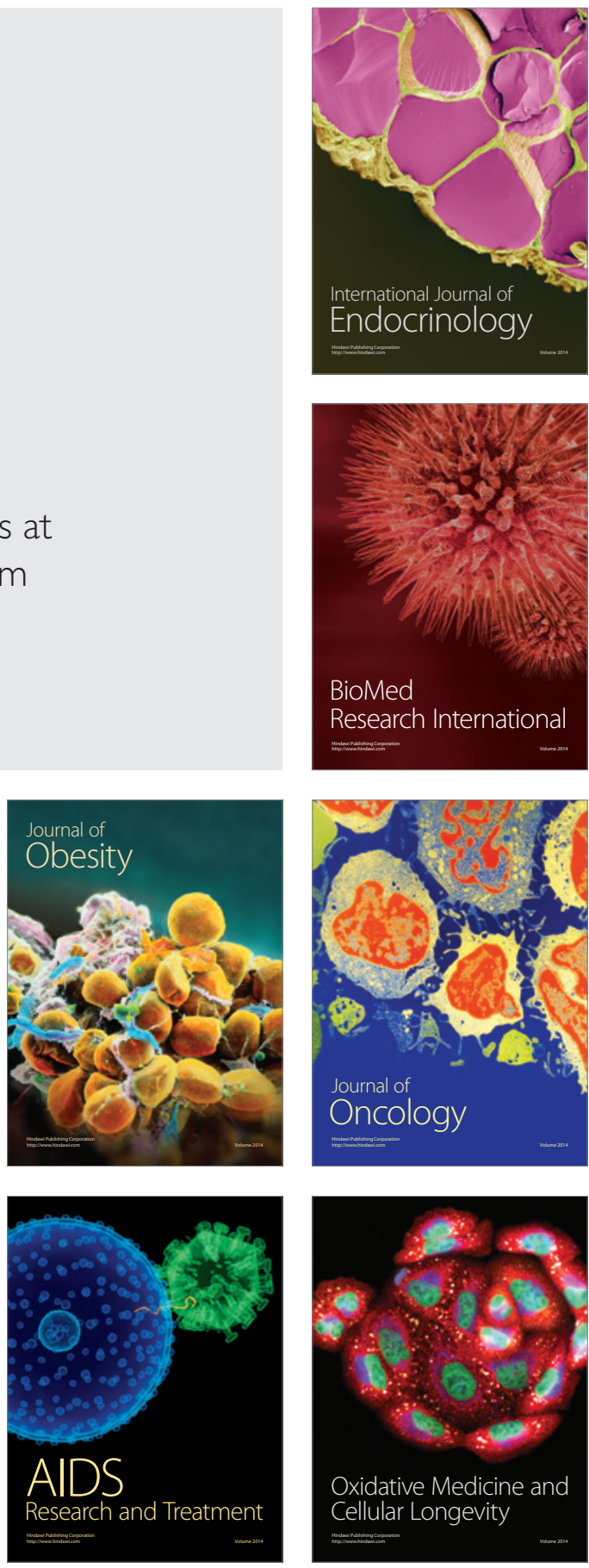